\title{
China's Pattern of Growth: MOVing To Sustainability AND REDUCING INEQUALITY
}

\author{
Louis Kuijs ${ }^{1 / *}$ and Tao Wang ${ }^{2 / *}$
}

\begin{abstract}
This paper studies the sources and pattern of China's impressive economic growth over the last 25 years, and shows that key issues currently of concern to policymakers - widening inequality, rural poverty, and resource intensity - are to a large extent rooted in China's growth strategy, and resolving them requires a rebalancing of policies. Using both macro level and sector data and analyses, the paper extends the growth accounting framework to decompose the sources of labor productivity growth. We find that growth of industrial production, led by a massive investment effort that boosted the capital/labor ratio, has been the single most important factor driving GDP and overall labor productivity growth since the early 1990s. The shift of labor from lowproductivity agriculture has been limited, and, hence, contributed only marginally to overall labor productivity growth. The productivity gap between agriculture and the rest of the economy has continued to widen, leading to increased rural-urban income inequality. Looking ahead, we calibrate two alternative scenarios. We show that continuing with the current growth pattern would further increase already high investment and saving needs to unsustainable levels, lower urban employment growth, and widen the rural-urban income gap. Instead, reducing subsidies to industry and investment, encouraging the development of the services industry, and reducing barriers to labor mobility would result in a more balanced growth with an investment-to-GDP ratio that is consistent with medium-term saving trends, faster growth in urban employment, and a substantial reduction in the income gap between rural and urban residents.
\end{abstract}

Keywords: Sources of growth; pattern of growth; labor productivity; labor relocation; income inequality; sustainability of growth; China.

JEL Classification: E22, E23, E24, J21, O11, O14, O15, O40, O53.

World Bank Policy Research Working Paper 3767, November 2005

The Policy Research Working Paper Series disseminates the findings of work in progress to encourage the exchange of ideas about development issues. An objective of the series is to get the findings out quickly, even if the presentations are less than fully polished. The papers carry the names of the authors and should be cited accordingly. The findings, interpretations, and conclusions expressed in this paper are entirely those of the authors. They do not necessarily represent the view of the World Bank, its Executive Directors, or the countries they represent. Policy Research Working Papers are available online at http://econ.worldbank.org.

1/ World Bank, Beijing Office (EASPR). Email: akuijs@worldbank.org

2/ International Monetary Fund. Email: taowanghome@yahoo.com

* We thank Bert Hofman for encouragement and comments. We also thank the participants of the Chongqing Conference of the China Economist Society in June 2005 for comments. 


\section{INTRODUCTION}

China's GDP growth has averaged 9.4 percent per annum since 1978. As a result of this impressive growth, millions of people were lifted out of poverty. Economic reforms implemented over the last 25 years have certainly been instrumental in the remarkable growth performance, leading to higher productivity growth than in the pre-reform period. Nevertheless, it is widely agreed that China's growth during this period has been resource intensive, drawing heavily on physical capital, energy, and natural resources. In recent years, growth has also been associated with rising inequality. As China increasingly faces a widening rural-urban income divide and heavy demands on energy, water and other natural resources, and with savings expected to decline in the medium term, concerns are growing about the quality and sustainability of China's growth.

In this paper we: (1) identify some key features about the growth experience; (2) demonstrate the link between the pattern of growth and the effect on urban employment and income distribution; and (3) present two scenarios to answer the following questions: how sustainable is the current type of growth, and what kind of policy adjustment are necessary to achieve the government's goals of urban employment growth and reduction of inequality?

\section{KEY FEATURES OF CHINA'S GROWTH}

\subsection{Sources of Growth: Capital, Labor, and Total Factor Productivity}

A number of studies have used growth accounting to analyze the sources underlying China's growth of the past 25 years. These studies assume a certain production technology and try to assess to what extent factor accumulation and total factor productivity (TFP) contributed to growth (see Heytens and Zebregs (2003) for a summary). While estimates differ due to variations in assumptions, the studies have converged on a number of findings. TFP growth contributed significantly to GDP growth, having increased since the introduction of reforms at the end of the 1970s. Estimates of TFP growth during the reform period range between 2 and 4 percent per year. These studies also find that the contribution of physical capital accumulation has been large, reflecting a high and increasing investment to GDP ratio. Consistent with slowing overall employment growth, the contribution of labor growth has been modest, especially over the last decade.

Our own growth accounting exercise for the 1978-2004 period finds similar results. We assume Cobb-Douglas technology, and a capital-output ratio of 2.4 in 1978 (as in Wang and Yao (2002), Chow (1993), and Hu and Khan (1997)), depreciation of 5 percent per year (as in Wang and Yao (2002)), and an elasticity of output with respect to labor of 0.5 . We estimate that growth in the capital stock, which has averaged 10 percent per year, has contributed to more than half of GDP growth; TFP growth, at 3.3 percent per annum, contributed another one-third; and employment growth contributed the modest remainder.

Moreover, splitting the sample into two periods, we find that, between 1993 and 2004, the contribution of capital accumulation to GDP growth was even higher, at 62 percent, while TFP growth slowed somewhat to 2.7 percent per year, contributing about 30 percent of GDP growth. Total employment growth has been very modest, accounting for only 6 percent of GDP growth. Meanwhile, the capital-output ratio is estimated to have risen from 2.2 in 1994 to 2.8 in 2004, reflecting the rapid investment growth in the last decade. 
An alternative way of looking at these trends is to decompose labor productivity growth. Using the relationships from the Cobb-Douglass production function underlying the growth accounting exercise, we can decompose labor productivity growth into TFP growth and a term related to the increase in capital-intensity (the increase in the capital-labor ratio).

Equation (1) is the standard Cobb-Douglass production function:

$\mathrm{Y}=\mathrm{AL}^{\alpha} \mathrm{K}^{1-\alpha}$

where $\mathrm{Y}$ is real GDP, A is total factor productivity (TFP), L is employment, and $\mathrm{K}$ is the capital stock (in constant prices). From this equation, we derive the expression for labor productivity:

$\mathrm{Y} / \mathrm{L}=\mathrm{A}(\mathrm{K} / \mathrm{L})^{1-\alpha}$

or

$\mathrm{y}=\mathrm{Ak}^{1-\alpha}$

where $y=Y / L$, and $k=K / L$. From (2), the change in labor productivity over time is

$\partial(\mathrm{y}) / \partial \mathrm{t}=\mathrm{k}^{1-\alpha} \partial \mathrm{A} / \partial \mathrm{t}+\mathrm{A}(1-\alpha) \mathrm{k}^{-\alpha} \partial(\mathrm{k}) / \partial \mathrm{t}$

Labor productivity growth can then be written as:

$\partial(\mathrm{y}) / \partial \mathrm{t} / \mathrm{y}=\mathrm{k}^{1-\alpha} \mathrm{y}^{-1} \partial \mathrm{A} / \partial \mathrm{t}+\mathrm{A}(1-\alpha) \mathrm{k}^{-\alpha} \mathrm{y}^{-1} \partial \mathrm{k} / \partial \mathrm{t}$

With some manipulation, the above can be written as:

$g(y)=g(A)+(1-\alpha) * g(k)$

where $g(x)$ denotes $\partial(x) / \partial t / x$, the growth rate of $x$.

We find that between 1978 and 1993, labor productivity rose by 7.0 percent on average each year while employment grew by 2.5 percent per annum. Slightly more than half of the increase in labor productivity stemmed from TFP growth, and the rest from the rise in the capital-labor ratio (Table 1). During 1993-2004, when investment as a share of GDP increased significantly, labor productivity rose by 7.8 percent per annum on average while employment growth declined to just over 1 percent a year. In this period, the contribution of TFP growth to labor productivity growth declined and the contribution of capital intensity rose to two-thirds. ${ }^{1}$ These results underscore the increased importance of capital accumulation over the last decade.

\subsection{Sectoral Trends-the Role of Structural Changes and Shifts of Labor between Sectors}

Standard economic theory on development predicts that in a country with a large pool of surplus labor occupied in low-productivity agriculture, rapid growth and industrialization result in the relocation of agricultural labor into the non-agricultural sectors, where employment increases rapidly. ${ }^{2}$ In the process, overall labor productivity increases because: (i) labor shifts from a less

\footnotetext{
${ }^{1}$ Heytens and Zebregs (2003) assume varying TFP growth throughout the reform period and find some, but relatively modest, variation.

${ }^{2}$ See for instance Lewis (1954).
} 
productive sector to more productive sectors, and (ii) "organic" productivity increases in each sector because of technology and institutional effects.

Table 1. Sources and aspects of growth (1978-2004)

(average annual increase, in percent)

\begin{tabular}{ccc} 
& $1978-93$ & $1993-2004$ \\
\hline GDP growth & 9.7 & 9.0 \\
Employment growth & 2.5 & 1.1 \\
$\quad$ Urban employment growth & 5.2 & 2.9 \\
Labor productivity growth & 7.0 & 7.8 \\
$\quad$ From TFP growth & 3.7 & 2.7 \\
$\quad$ From increasing K/L ratio & 3.2 & 5.1 \\
Memorandum item (in percent) & & \\
Investment/GDP ratio & 30.2 & 36.8 \\
At end-period & \multicolumn{2}{c}{4} \\
Share employment in agriculture & 56.4 & 46.9 \\
\hline
\end{tabular}

Source: NBS, and authors' estimates.

The economy-wide capital-labor ratio should increase along the way because labor moves from a less capital-intensive sector to more capital intensive ones, and the sectors themselves also become more capital intensive. As labor moves out of agriculture, productivity there increases, and the productivity gap between agriculture and the other sectors declines over time. Therefore, as the economy grows, the share of employment in agriculture declines. Using cross-country data, figure 1 confirms the strong association between economic development and the share of total employment in agriculture.

Figure 1. China and other countries: agricultural employment share and GDP per capita, (2001, unless otherwise specified)

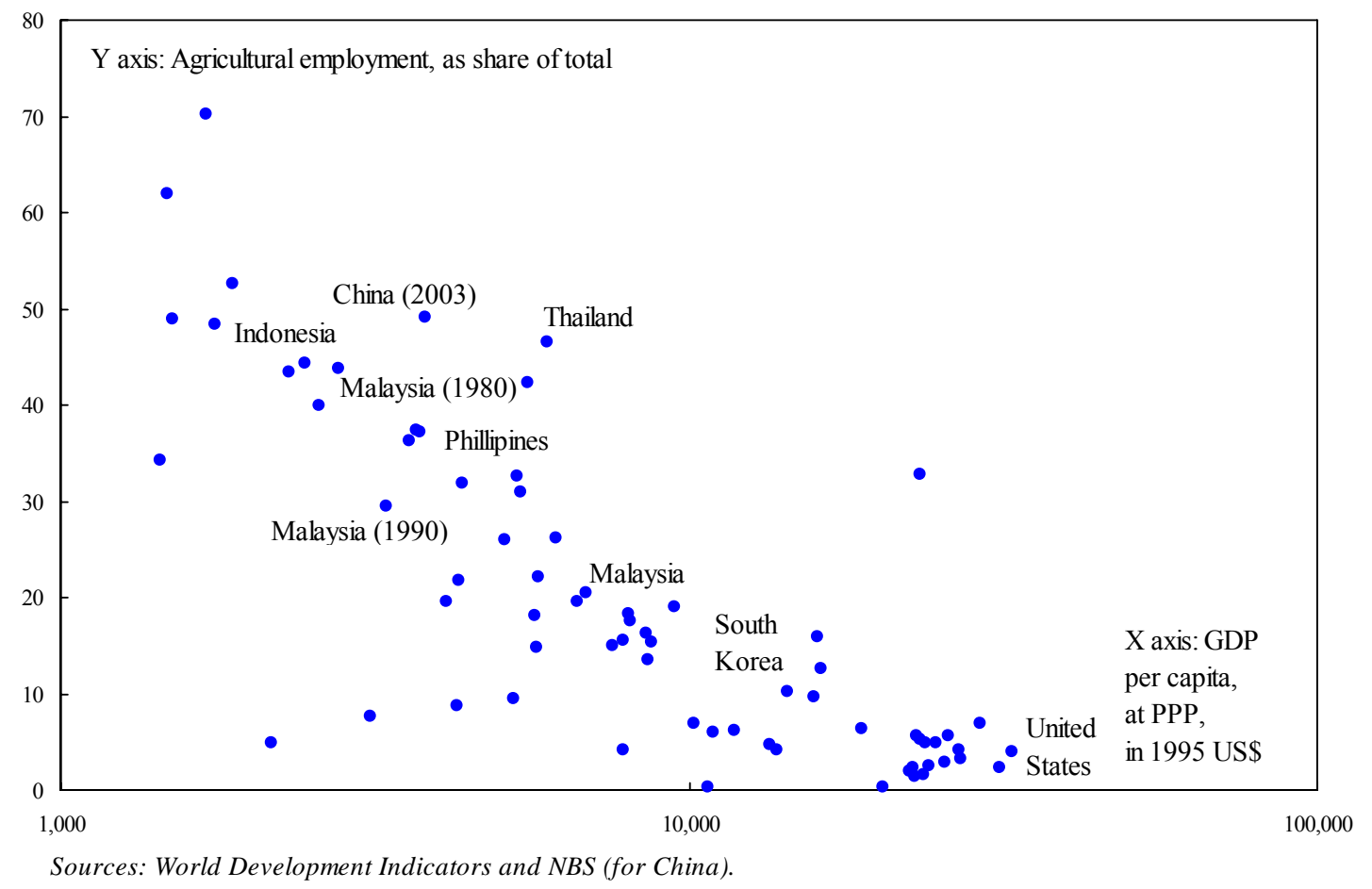


This pattern was replicated in China in the first 15 years of the reform period, but not since the mid-1990s. The share of agriculture in total employment declined from 70 percent in 1978 to 50 percent in 1996 (Figure 2). However, since the mid-1990s, only limited further movement has taken place, in part also because of the demise of the township and village enterprises. In particular, after rising during the 1980s, the share of employment in industry has remained fairly stable since the end of the 1980s, despite remarkable growth in industry. Labor relocation from agriculture to services has been modest since the early 1990s, at $3 / 4$ percentage point of total employment per year. As a result, China now has a relatively high share of total employment in agriculture compared to other countries at a similar stage of development, although the shift out of agriculture in 2004 was significant.

Figure 2. Employment share

(in percent of total)

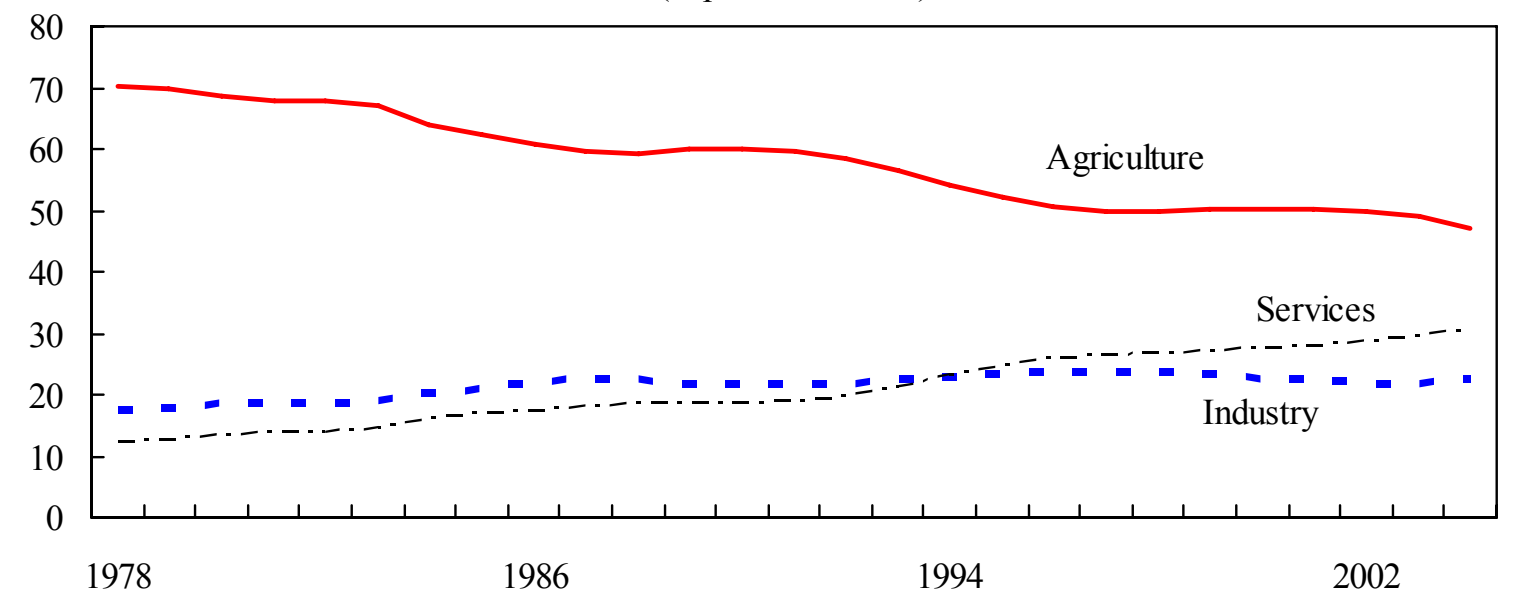

Sources: NBS, and authors' estimates.

In the meantime, agriculture's productivity gap with other sectors in China is high and rising (Figure 3). The ratio of productivity in industry and agriculture has been increasing spectacularly, from 5 in 1993 to a whopping 9 times in 2003 (in constant prices) - among the highest

Figure 3. Labor productivity

(1995 RMB, 000s per employee)

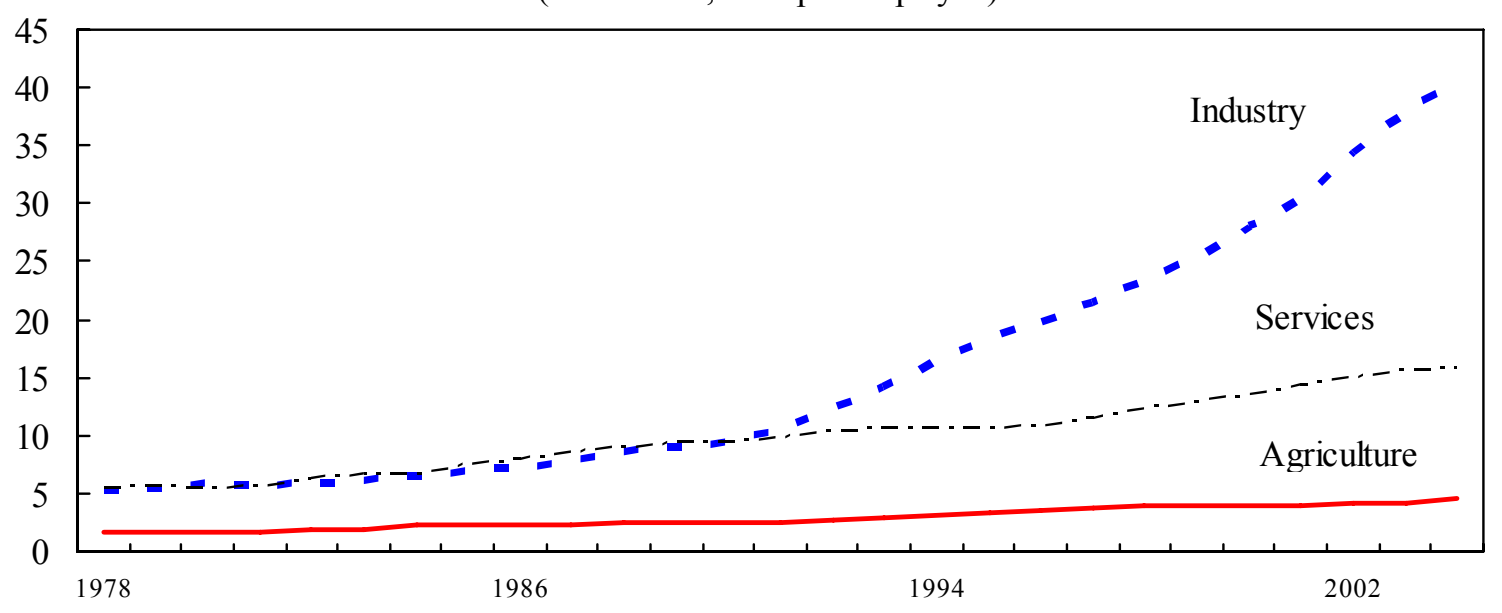

Sources: NBS, and authors' estimates. 
internationally. ${ }^{3}$ Labor productivity in services has been between 3.4 and 3.7 times as high as in agriculture (in constant prices) (this ratio has been unchanged since 1993 at around 3.7). ${ }^{4}$

\section{IDENTIFYING CHINA'S PATTERN OF GROWTH AND POLICY FACTORS}

Given the large surplus labor and large productivity gap between agriculture and the rest of the economy, why has so little reallocation of labor from agriculture to the higher productivity sectors taken place? Why has China's economic growth led to such modest urban employment growth? The answer is directly tied to China's growth pattern and the associated policies pursued.

China's pattern of growth especially since the early 1990s can be characterized as follows:

- The bulk of GDP growth since the early 1990s has come from explosive growth of industrial production. Industrial value added increased on average over 11 percent per year during 1993 and 2004, and the share of industry in GDP rose from 38 percent in 1990 to 53 percent in 2004 (Figure 4), the highest among countries for which the World Bank's World Development Indicator database has data. In 2002-04, industry contributed around 2/3 of GDP growth.

Figure 4. Shares in value added

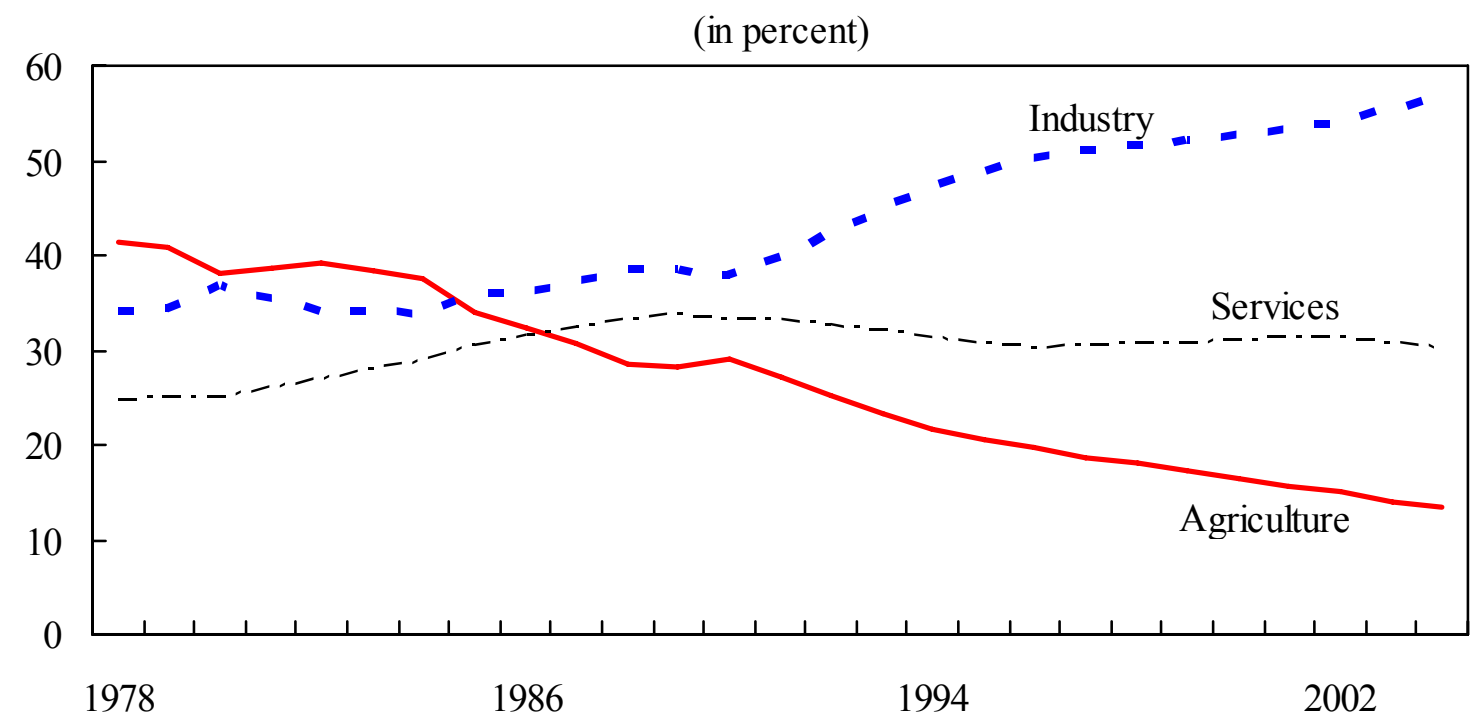

Source: NBS, and authors' estimates.

Over 90 percent of the growth in industry in 1993-2004 was in the form of labor productivity growth rather than employment growth, mainly led by a large-scale investment effort and increased capital-labor ratio. As a result, absorption of agricultural surplus labor was largely left to the service sector, and has been limited since the mid 1990s. Urban employment growth slowed from 5.4 percent per year during 1978-93 to 2.9 percent during 1993-2004.

\footnotetext{
${ }^{3}$ The definition for industry used here is that of the "secondary" sector in the Chinese statistics, which includes mining (3.4 percent of GDP in 2003) and construction (7 percent of GDP in 2003).

${ }^{4}$ In current prices, the gap has varied more over time, as the terms of trade for agriculture have varied.
} 
- The slow relocation of rural labor has hampered productivity growth in agriculture.

Productivity is by far the most important determinant of income per worker. With overall agricultural output growth modest - and not, at the margin, depending significantly on the number of workers - the slow shift of labor has meant that per capita rural income growth has been low, leading to the widening rural-urban inequality. Indeed, the development of the productivity differentials can explain the development of the urban-rural income gap rather well (Figure 5).

Figure 5. Productivity gap between agriculture and other sectors and the urban-rural income gap

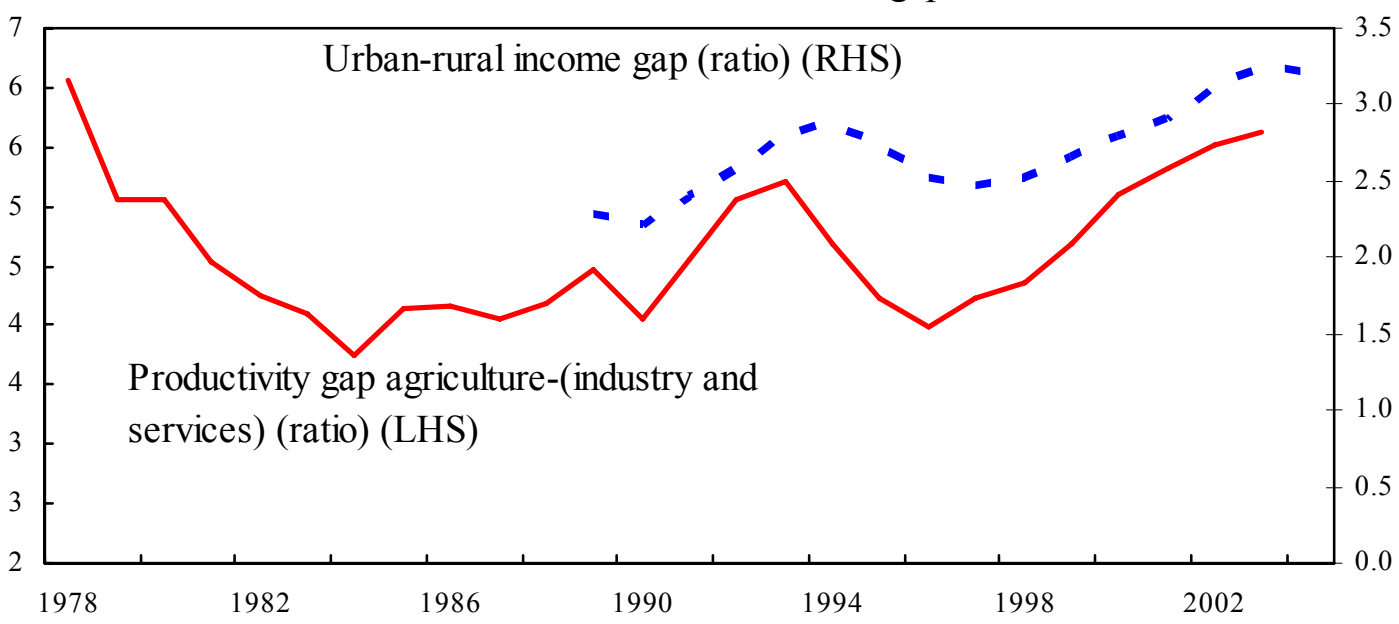

Source: NBS, and World Bank staff estimates.

To further illustrate these findings, we decompose overall labor productivity growth into components related to a shift of labor between sectors and components related to "organic" productivity growth in each sector. Overall labor productivity $\mathrm{Y} / \mathrm{L}$ is just

$\left(\mathrm{Y}_{1}+\mathrm{Y}_{2}+\mathrm{Y}_{3}\right) /\left(\mathrm{L}_{1}+\mathrm{L}_{2}+\mathrm{L}_{3}\right)$, where $\mathrm{Y}_{\mathrm{i}}, \mathrm{L}_{\mathrm{i}}$ are production and labor in sector i respectively. This definition could be rewritten as

$\mathrm{y}=\varepsilon_{1} \mathrm{y}_{1}+\varepsilon_{2} \mathrm{y}_{2}+\varepsilon_{3} \mathrm{y}_{3}$

where $\mathrm{y}$ is overall labor productivity, and $\mathrm{y}_{\mathrm{i}}$ is labor productivity in sector $\mathrm{i}$, and $\varepsilon_{\mathrm{i}}$ is the share of sector $\mathrm{i}$ in total production. The derivative of the above equation is:

$\partial \mathrm{y} / \partial \mathrm{t}=\partial \varepsilon_{1} / \partial \mathrm{t}^{*} \mathrm{y}_{1}+\varepsilon_{1} \partial \mathrm{y}_{1} / \partial \mathrm{t}+\partial \varepsilon_{2} / \partial \mathrm{t}^{*} \mathrm{y}_{2}+\varepsilon_{2} \partial \mathrm{y}_{2} / \partial \mathrm{t}+\partial \varepsilon_{3} / \partial \mathrm{t}^{*} \mathrm{y}_{3}+\varepsilon_{3} \partial \mathrm{y}_{3} / \partial \mathrm{t}$

which means that the growth of overall labor productivity can be written as

$\mathrm{g}(\mathrm{y})=\mathrm{g}\left(\varepsilon_{1}\right) * \mathrm{y}_{1} / \mathrm{y}+\varepsilon_{1} \mathrm{~g}\left(\mathrm{y}_{1}\right) \mathrm{y}_{1} / \mathrm{y}+\mathrm{g}\left(\varepsilon_{2}\right) * \mathrm{y}_{2} / \mathrm{y}+\varepsilon_{2} \mathrm{~g}\left(\mathrm{y}_{2}\right) \mathrm{y}_{2} / \mathrm{y}+\mathrm{g}\left(\varepsilon_{3}\right)^{*} \mathrm{y}_{3} / \mathrm{y}+\varepsilon_{3} \mathrm{~g}\left(\mathrm{y}_{3}\right) \mathrm{y}_{3} / \mathrm{y}$.

The first, third, and fifth terms combined capture the shift of labor between sectors, and the second, fourth, and sixth denote organic productivity growth in the three sectors. The decomposition results are shown in Table 2, and they confirm that the shift of labor from agriculture to other sectors has not been an important factor behind GDP growth in China, and "organic" labor productivity growth in industry is by far the most important factor. 
In 1993-2003, the shift of labor into higher-productivity sectors contributed on average only 0.8 percentage point to overall productivity growth of 7.7 percent per year. On the other hand, "organic" productivity growth in industry, contributed a spectacular 5.2 percentage point to overall productivity growth $(2 / 3$ of the total).

Concerns about the quality of China's macroeconomic data warrant caution. However, as illustrated in the Annex, data issues are unlikely to change the conclusions of the paper materially.

Table 2. China: sectors' contribution to overall labor productivity growth (1978-2004) (average annual increase, in percent)

$1978-93 \quad 1993-2004$

\begin{tabular}{ccc}
\hline Labor productivity $1 /$ & 6.7 & 7.7 \\
From shifts in employment b/t sectors & 1.2 & 0.8 \\
From organic productivity increase in sectors & 5.5 & 7.0 \\
Agriculture & 1.0 & 0.5 \\
industry & 2.7 & 5.2 \\
Services & 1.4 & 1.1 \\
\hline
\end{tabular}

Sources: NBS, and authors' estimates.

1/ Artithmetic average, implying small differences with geometric averages used in the rest of the paper.

The important roles of capital and industry in China's economy are of course related. Industry requires more physical capital per worker than the service sector, and, accordingly, the share of income distributed to workers is lower in industry than in the services sector. Indeed, countries where industry is more important tend to invest more.

The growth pattern described above generated very high GDP growth for China with only moderate urban employment growth, strikingly at odds with the theoretical expectation and most analyses/assumptions of what has happened in China. Indeed, the persistence and widening of large sectoral labor productivity gaps and the lower-than-expected flow of labor in the presence of those gaps points to market imperfections and/or government intervention. In the absence of market imperfections and government intervention, (i) more investment would be expected to take place in sectors other than industry, where the true marginal return to capital should be much higher than in industry; and (ii) labor should flow into industry where labor productivity is much higher than in other sectors.

The current pattern of growth and resulting consequences for resource intensity and income inequality could be linked to the growth strategy the government has pursued in the past. The government has subsidized and favored industry and investment over the services sector and domestic consumption, especially at the local level, maybe partly because of incentives created by the system guiding promotion of local officials and the tax system, including the productionbased value added tax. For example:

- Industrialization was promoted by keeping the prices of energy, electricity, utilities (including water), and land low and by not having sufficiently strict environmental regulations or enforcement. While several energy subsidies have been removed, cheap 
electricity for industry, due to subsidies on coal for power generation, continues to encourage the establishment of electricity-intensive industry (Bugs 2005).

- Financing was channeled on favorable terms to investment in industry, particularly to large enterprises and/or SOEs. Under the traditional financial system, the interest rate has been low for those who have had access, which has promoted capital intensive development in industry. The People's Bank of China (2004) estimates that small and medium-sized enterprises - which are significantly more prevalent in services than in industry - account for more than half of GDP but receive less than 10 percent of total bank loans. The government's channeling of financing to investment in infrastructure has also traditionally benefited industry in particular.

- Development of the services sector was not sufficiently stimulated. Service sector development suffers from restrictions and regulation and a lingering bias against private ownership (World Bank (2003)).

- Labor movements were restricted due to the Hukou system (Whalley and Zhang (2004)), discriminating regulations against migrant workers, non-portable labor and social benefits, and land tenure policies. Migration has taken place to a large extent only in the form of "floating" population.

The overall result has been a subsidization of current production in industry, vis-à-vis current production in other sectors, future production, and environmental quality. The favoring of industry and investment does two things: in addition to the economic and social implications described above, the subsidization of input prices encourages a non-economic and not-sustainable use of energy and primary commodities, and degradation of the environment.

\section{IMPLICATIONS FOR THE FUTURE: SUSTAINABILITY OF GROWTH AND NECESSARY POLICY ADJUSTMENTS}

In this section, we calibrate two scenarios to illustrate the future implications of the continuation of the current growth pattern and the pay-off of a change in growth strategy and associated policies. The scenario on current policies assumes an unchanged growth strategy with current trends continuing, and an alternative scenario assumes less emphasis on and subsidization of industry and investment. The projections are made extending the growth accounting and sectoral shift analysis discussed in sections 2 and 3 . The assumptions underlying the two scenarios are summarized in Table 3.

As shown in Table 4, continued investment and industry-led growth in the scenario on current policies is almost certainly unsustainable. It would require the investment-to-GDP ratio reaching unprecedented high levels of 55 percent on average in 2014-24 in order to maintain GDP growth of 8 percent per year. In addition, the emphasis of continued investment in the industrial sector means that limited resources are devoted to development of the services industry. As a result, there would continue to be only moderate urban employment growth and a moderate labor flow out of agriculture, leaving a large share of people poor in agriculture. The productivity gap between agriculture and the rest of the economy would rise from an already high 6 times to over 8 times by 2024, further widening the rural-urban income divide. In 2024, 33 percent of total employment would still be employed in agriculture, a high share for a country with a per capita income of $\$ 20,000$ at that time (in 1995 prices). Resource intensity and environmental problems would also likely continue to intensify. 
Table 3. Scenario assumptions

\section{Scenario on current policies:}

- Annual GDP growth of 8 percent until 2024, driven by capital intensive growth in industry;

- Annual overall employment growth of 0.4 percent between 2004-14, and 0 percent between 2014-24, largely driven by demographics; ${ }^{5}$

- A shift of labor from agriculture into services of 0.8 percentage point per year, as during 1993-2004;

- A small annual decline in the share of employment in industry, as during 1993-2004;

- Annual labor productivity growth in industry of 9.3 percent in 2004-24, compared to 10 percent in 1993-2004;

- Annual overall TFP growth of 2.7 percent, as achieved during 1993-2004.

\section{Scenario with rebalanced policies:}

- Annual real GDP growth of 8 percent until 2024, driven by more balanced growth between services and industry, and between TFP growth and urban employment on the one hand, and capital accumulation on the other hand;

- Annual overall employment growth of 0.8 percent between 2004-14, and 0.4 percent between 2014-24; ${ }^{6}$

- A shift of employment from agriculture into services of about 1.8 percentage point per year, as growth in services is stronger;

- A similarly small decline in the share of industry in total employment;

- Annual labor productivity growth in industry of 6.3 percent in 2004-24;

- Annual overall TFP growth of 3.5 percent, with most of the increase (compared to the scenario on current policies) coming from more reallocation of labor.

Under the alternative scenario, growth would be more balanced: (i) between services and industry; and (ii) between TFP growth and urban employment on the one hand, and capital accumulation on the other hand. Continued rapid growth will require much less overall capital accumulation, with a more sustainable investment-to-GDP ratio (averaging 36 percent in 2014-24 compared to 45 percent in 2004). This lower overall investment-to-GDP ratio would be more consistent with prospective long-term trends in demographics and saving. With less capital accumulation in industry and more investment in services, which is more labor intensive, urban employment will grow over $1 \frac{1}{2}$ percentage points per year faster, leading to more transfer of labor out of agriculture. As a result, labor productivity in agriculture will rise much faster, supporting higher incomes there. The decrease in the productivity gap between agriculture and the other sectors from 6 now to less than 3 by 2024 will strongly reduce urban-rural income

\footnotetext{
${ }^{5}$ Given the very low benefits in China's welfare system for most types of people, the natural unemployment rate will remain very low. Rather than assuming significant fluctuations in unemployment in the medium term, we assume no change in the unemployment ratio. For simplification, we assume that employment will grow in line with labor force growth, and that both will continue to lag growth of the working population age, continuing a trend of falling participation and employment rates.

${ }^{6}$ With a policy setting more in favor of employment creation, employment is assumed to grow in line with the working population (aged 15-64).
} 
inequality. Finally, a lower share of industry in GDP will lower the resource intensity of growth and mean less environmental degradation.

Table 4. China: Sources and aspects of growth (1993-2024)

(in percent)

\begin{tabular}{|c|c|c|c|c|c|}
\hline & \multirow[b]{2}{*}{ 1993-2004 } & \multicolumn{2}{|c|}{ On current policies } & \multicolumn{2}{|c|}{ With rebalanced policies } \\
\hline & & $2004-14$ & 2014-2024 & $2004-14$ & $2014-2024$ \\
\hline GDP growth 1/ & 9.0 & 8.0 & 8.0 & 8.0 & 8.0 \\
\hline Total employment growth & 1.1 & 0.4 & 0.0 & 0.8 & 0.4 \\
\hline Urban employment growth & 2.9 & 1.7 & 1.2 & 3.4 & 2.9 \\
\hline Labor productivity growth & 7.8 & 7.6 & 8.0 & 7.2 & 7.6 \\
\hline From TFP growth & 2.7 & 2.7 & 2.7 & 3.5 & 3.5 \\
\hline From increasing capital-labor rati & 5.1 & 4.9 & 5.3 & 3.7 & 4.1 \\
\hline \multicolumn{6}{|c|}{ Memorandum item (period average, in percent) } \\
\hline Investment/GDP ratio & 36.8 & 43.4 & 55.3 & 34.5 & 36.4 \\
\hline \multicolumn{6}{|l|}{ At end-period } \\
\hline Share employment in agriculture & 46.9 & 41.1 & 33.4 & 31.3 & 12.5 \\
\hline $\begin{array}{l}\text { Ratio productivity non agriculture- } \\
\text { agriculture }\end{array}$ & 5.7 & 7.3 & 8.2 & 4.7 & 2.3 \\
\hline
\end{tabular}

Source: NBS, and authors' estimatates.

1/ Potential GDP growth (in 2005, actual GDP growth is assumed to differ from potential GDP growth, in 2006-2024, actual GDP growth is assumed to equal potential GDP growth).

Looking at international experience, the outcomes of the alternative scenario are quite achievable if policies are rebalanced. For example, the illustrative movement of the employment share of agriculture from 48 percent in 2004 to 15 percent in 2024 compares to a similar pace in South Korea, where it was reduced from 50 percent in 1973 to 10 percent in 2001. Malaysia decreased its agricultural employment from 37 percent in 1980 to 18.4 in 2001. 


\section{REFERENCES}

Bugs (2005), "Cost Comparison for Manufacturing - China and India", Presentation at Conference on "China, an Indian Opportunity" in Bangalore and Hyderabad, India.

Chow, Gregory, "How and Why China Succeeded in her Economic Reform," China Economic Review, 4 (Fall 1993), pp. 117-128, 1993.

Heytens, Paul and Harm Zebregs, "How Fast Can China Grow?" In Tseng, Wanda, Rodlauer, Markus (Eds), China Competing in the World Economy. International Monetary Fund, Washington, DC, 2003.

Hu, Zuliu and Moshin Khan, "Why is China Growing so Fast?" IMF Working Paper No. 96/75, 1997.

Lewis, A.W. "Economic Development with Unlimited Supplies of Labor", Manchester School of Economic and Social Studies 22: 139-91, 1954.

People's Bank of China (2004), Survey on SME Financing Structure in China.

Wang, Yan and Yudong Yao, "Sources of China's Economic Growth 1952-1999: Incorporating Human Capital Accumulation," China Economic Review 116, 2002.

Whalley, John and Shunming Zhang (2004). "Inequality Change in China and (Hukou) Labor Mobility Restrictions.” NBER Working Paper 10683. Cambridge, Mass.: National Bureau of Economic Research.

World Bank, Country Economic Memorandum, Washington, DC, 2003.

China Statistical Yearbook, various issues. 


\section{Annex - Concerns about the data and the impact on the conclusions of this paper}

While concerns about the quality of China's macroeconomic warrant caution, they are unlikely to change the conclusions of this paper substantially.

First, there are concerns about how the "floating population is treated in the labor statistics. The floating population consists of people from rural areas who work in urban areas. They may not be correctly measured as working in services or industry, which would underestimate actual urban employment growth. The floating population is now estimated at about 140 million, up from 30 million in 1983 and 75 million in 1995, and floating employment is now estimated at 100 million. We assume that 30 percent of the floating population works in industry, and 70 percent in services. Under the extreme assumption that all the floating employment is incorrectly counted as working in agriculture, and adjusting for that, the contributions to overall productivity growth would actually change little. The macro-economic implications summarized in Table 1 would not be affected. In terms of Table 2, the contribution of the labor shift would increase to 0.9 percentage point, and the contribution of organic productivity growth in industry would be 4.8 percentage points, still by far the largest component. The productivity gap between agriculture and other sectors would be significantly lower (3.3 in 2004, compared to 5.7). But even under this extreme assumption, the productivity gap between agriculture and industry would increase over time, from 3.9 in 1993 to 5.4 in 2004.

Second, the size and growth of the services industry may be larger than the official data indicate. Making an extreme assumption that GDP is 30 percent underestimated purely on account of an underestimated services industry (that is, doubling the size of the services industry in 2004), up from an assumed 15 percent in 1993, would imply: (i) a lower investment to GDP ratio in 2004 (33.7 compared to X); (ii) a lower capital stock to GDP ratio (2.2 compared to 2.8); and (iii) higher average TFP growth during 1993-2004-by 1.2 percentage point. But the contribution to labor productivity of an increasing capital-labor ratio would still be 5.1 out of 9 percentage points. 